\author{
Military Technical College \\ Kobry Elkobbah, Cairo, \\ Egypt.
}

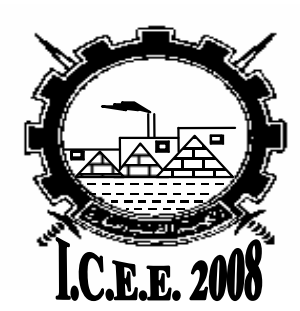

$4^{\text {th }}$ International Conference On Chemical \& Environmental Engineering

27-29 May 2008

\title{
INFLUENCES OF MOLD TEMPERATURE AND VACUUM ON THE RESIN TRANSFER MOLDED POLYMER COMPOSITE PLATES
}

\author{
AKGUL $^{*} E$. and KAYNAK ${ }^{* *}$ C.
}

\begin{abstract}
The purpose of this study is to investigate the influences of mold temperature and vacuum on the mechanical properties of epoxy matrix woven glass fiber reinforced composite specimens produced by Resin Transfer Molding (RTM). For this purpose, six different mold temperatures $\left(25^{\circ}, 40^{\circ}, 60^{\circ}, 80^{\circ}, 100^{\circ}, 120^{\circ} \mathrm{C}\right)$ and under vacuum and without vacuum conditions are used. Specimens are characterized by using ultrasonic C-Scan inspection, mechanical tests (Tensile, Impact), and scanning electron microscopy (SEM). It is observed that mechanical properties of the specimens produced with a mold temperature of $60^{\circ} \mathrm{C}$ proved to be the highest (e.g. $16 \%$ higher tensile strength and $43 \%$ higher Charpy impact toughness). Without the application of vacuum, the percentage of "voids" increased leading to deterioration of mechanical properties, as $26 \%$ loss in Charpy impact toughness and $5 \%$ loss in tensile strength.
\end{abstract}

\section{KEYWORDS:}

Epoxy, Woven Glass Fibers, RTM, Mold Temperature, Vacuum

Graduate student, Middle East Technical University, Metallurgical and Materials Eng. Dept. Ankara, Turkey

** Professor, Middle East Technical University, Metallurgical and Materials Eng. Dept. Ankara, Turkey 


\section{INTRODUCTION}

Resin Transfer Molding (RTM) is an important composite production method. It involves injection of a pressurized mixture of thermosetting resin into a closed mold cavity where a fiber preform has been placed. There are various process parameters affecting the quality of the product, such as fiber fraction, resin injection pressure, fiber architecture, location of injection and ventilation gates, level of applied vacuum, resin and preheated mold temperatures.

Chang et al. [1] investigated the effects of process variables on the quality of compression resin transfer molded epoxy/glass fiber parts. Pre-heated mold temperatures of $25^{\circ}, 50^{\circ}$ and $75^{\circ} \mathrm{C}$ were used and the conclusion was that the influence of mold temperature on the mechanical properties of RTM parts was less significant when compared to that of vacuum level, injection pressure and resin temperature. Yu and Young [2] studied the optimum process parameters in RTM for epoxy/glass fiber composites, one of them being the mold temperature. It was shown that under the same injection pressure, mold filling time was shorter for higher initial mold and resin injection temperatures. However, it was stated that too high a filling temperature might cause incomplete mold filling due to premature resin gel. In a study concerning permeation improvement of epoxy/carbon fiber composites in vacuum assisted RTM by induction heating [3], it was shown that complete fiber wetout could be attained above a certain heating level. However, excessive mold heating might lead to premature gelling of the resin and higher unfilled volume fractions.

The application of vacuum at the vents in RTM is known to minimize the void content, to aid resin flow and to allow rapid mold filling. Some researchers indicated that tensile, flexural and shear strength values are enhanced with vacuum assistance. For instance, in the study of Chang et al. [1], specimens produced without the vacuum assistance were proved to possess higher void content and 30\% decreased ultimate tensile strength. Lundstrom and Gebart [4] compared the void content of parts produced with different levels of vacuum assistance. It was shown that the increasing applied vacuum results in decreased void content and the void content was negligibly small for the highest vacuum level $(\sim 0.001 \mathrm{MPa})$ used in their study. Hayward and Harris [5] investigated the effects of vacuum on the quality of RTM moldings with polyester resin. It was suggested that $70 \%$ vacuum assistance decreased the void content significantly and hence, shear and flexural strength of composites were improved. The reason behind the mechanical property improvements was stated as the reduced pressure in trapped air pocket which provides enhanced resin penetration into such regions.

The purpose of this study was to contribute RTM literature of epoxy/glass fiber composites by investigating the effects of preheated mold temperature and vacuum assistance during resin injection via using C-Scan ultrasonic inspection, mechanical tests and scanning electron microscopy. 


\section{EXPERIMENTAL}

The matrix material used is a mixture of a special low viscosity epoxy resin (Araldite LY5052) and hardener (Araldite HY5052) produced by Vantico (Switzerland) for RTM applications. The woven glass fiber reinforcement material used is CD 125-300 produced by Camelyaf (Turkey) with an $1 \times 1$ plain weave type having a surface density of $300 \mathrm{gr} / \mathrm{m}^{2}$.

The production of the composite plates is done by using ISOJET RTM System at BARIS Inc. (Turkey). It is composed of four main parts being an automated control unit, a vacuum pump unit, a resin mixing unit and a furnace for mold heating and resin curing. A two piece mold made of steel is used for the composite plate production The upper part of the mold has one inlet hole and two outlet holes while lower part has a rectangular cavity of $300 \times 200 \times 4 \mathrm{~mm}$.

First, inner faces of the mold halves are cleaned and waxed with Vantico QZ 13 mold releasing agent. Then, the preform is prepared by laying up 14 layers of woven glass fiber in the lower mold cavity. After that, upper face of the mold is closed and fastened, and then the mold is put in the furnace. After making inlet and outlet connections, the furnace is turned on to heat the mold to the prescribed temperature. In this study in order to investigate the effect of different mold temperatures on the mechanical properties of the composites, six different mold temperatures are utilized: $25^{\circ}, 40^{\circ}, 60^{\circ}, 80^{\circ}, 100^{\circ}$ and $120^{\circ} \mathrm{C}$. The resin and hardener mixture is prepared with a ratio of 100:38 parts by weight as indicated by the producer. In this study, a ratio of $500 / 190 \mathrm{gr}$ is used for the production of one plate. The mixture is stirred mechanically with a speed of $10 \mathrm{rpm}$ for 10 minutes in order to prevent inhomogeneous mixing of the resin and hardener due to the density difference. During mixing, in order to minimize bubble formation, vacuum degassing under $\sim 0.001$ bar is also accomplished. After all, the resin-hardener mixture is injected into the closed mold at 1.5 bar of injection pressure and at a mold vacuum level of 0.03 bar.

In order to investigate the effects of vacuum assistance, another set of six plates are produced at three different mold temperatures of $25^{\circ}, 60^{\circ}$, and $120^{\circ} \mathrm{C}$ under a vacuum level of 0.03 bar and without vacuum ( 1 bar). Following the mold filling, matrix resin system is cured in the mold for 3 hours at a temperature of $120^{\circ} \mathrm{C}$. After curing, composite plates produced are de-molded for sample preparation.

The composite plates are evaluated by a non-destructive testing method called Cscan by Tecal Auto-Ultra Scanning System, with a scanning program called Sara 8.2 and an evaluation software called NDEVAL 1.02 at TAI Ind. (Turkey). The frequency of the probe used was $5 \mathrm{MHz}$. The composite part is fixed to a bar, and then two probes approach to the part from each side leaving the thickness of the part between them. One probe emits ultrasonic waves while the other receives. Ultrasonic waves lose their energy and speed when they pass through the thickness of the composite plates. The magnitude of $\mathrm{dB}$ loss is altered when there is a defect in the structure, 
such as resin rich regions, fiber displacement, lack of resin impregnation and trapped air pockets.

After C-scan inspection of the composite plates, specimens for mechanical tests are cut by a circular saw cutting machine (Delta) at TAl machining shop. Specimens for each test are cut from different locations of the plates in order to have random sampling condition. By using the C-scan images of the composite plates, regions having large defects (especially edges of the plates) are considered not eligible for testing.

For each plate produced, at least three tension tests, and at least five Charpy impact tests are conducted at materials testing laboratories of TEMSA Co. (Turkey). In order to measure the mechanical properties of the specimens precisely, thickness and width of the central part of each specimen are measured from five different locations.

Tension tests are conducted according to ISO 527-4 by using a $10 \mathrm{kN}$ Shimadzu AGS-J universal testing machine with a loading rate of $2 \mathrm{~mm} / \mathrm{min}$. Type $1 \mathrm{~B}$ specimens (with a $10 \mathrm{~mm}$ width of a narrow portion and $115 \mathrm{~mm}$ length between

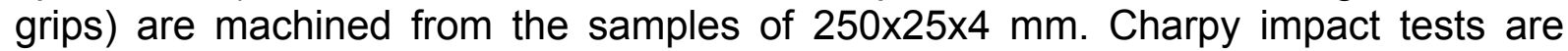
conducted according to ISO $179-1$ by using Ceast Resil Impactor 6959 with a hammer of 50 Joules. Dimensions of the un-notched specimen bars are $80 \times 10 \times 4 \mathrm{~mm}$ with a span length of $62 \mathrm{~mm}$.

Scanning electron microscopy is conducted especially to observe microvoids formed. Analysis is performed by using Jeol JSM-6400 microscope on the fracture surfaces of specimens spattered with gold to avoid charging.

\section{RESULTS AND DISCUSSION}

In the first part of this study, RTM composite plates were produced by using six different mold temperatures $\left(25^{\circ}, 40^{\circ}, 60^{\circ}, 80^{\circ}, 100^{\circ}\right.$, and $\left.120^{\circ} \mathrm{C}\right)$ under vacuum $(0.03$ bar) condition. Results of the mechanical tests of this set are given in Figure 1. Tension tests reveal that tensile strength of the specimens possess an increasing trend from $25^{\circ}$ to $60^{\circ} \mathrm{C}$ and a decreasing trend from $60^{\circ}$ to $120^{\circ} \mathrm{C}$ mold temperatures. Specimens produced under the condition of $60^{\circ} \mathrm{C}$ preheated mold temperature have $16 \%$ higher values than those of the specimens produced using $25^{\circ}$ and $120^{\circ} \mathrm{C}$ mold temperatures. A similar trend also holds for impact properties, that is, specimens produced using $60^{\circ} \mathrm{C}$ mold temperature possess $43 \%$ higher impact toughness when compared to specimens produced at $25^{\circ}$ and $120^{\circ} \mathrm{C}$.

Increased mold temperatures above room temperature basically can have three important effects on the resin mixture injected into the mold being, decrease in resin viscosity, decrease in resin gel time and thermal expansion of the micro bubbles 
present in the resin mixture. It is inevitable that the final structure includes microvoids due to incomplete degassing during mechanical stirring of resin and hardener, and insufficient fiber wetting occurring owing to the differences in micro and macro flow rates within the structure during resin injection. However, when the resin enters into a relatively hotter mold, there is a possibility that those voids can be mobilized and forced to move out of the structure by the cooperative action of vacuum and decreased resin viscosity. It has to be noted that an even higher mold temperature, the necessary decrease in viscosity can not be achieved due to increased crosslinking rate, so the present voids are immobilized preventing their ventilation through the outlets. This should explain the observation of the lowest void content and highest mechanical properties at an optimum preheated mold temperature.

It has been concluded that $60^{\circ} \mathrm{C}$ is an optimum mold temperature for the matrix resin system used in this study. SEM analysis confirmed the formation of excessive amounts of microvoids in the specimens below and above the mentioned optimum mold temperature (Figure 2).

In the second part of this study, another 6 plates were produced to investigate the effects of vacuum applied during molding, utilizing three different mold temperatures of $25^{\circ}, 60^{\circ}, 120^{\circ} \mathrm{C}$ with an initial resin/hardener mixture temperature of around $15^{\circ} \mathrm{C}$. Composite plates are produced both by applying vacuum ( 0.03 bar) and without using vacuum ( $\sim 1$ bar) at the prescribed mold temperatures. After that, plates are inspected by ultrasonic C-scan analysis. C-scan images (Figure 3 ) are first used to avoid specimen cutting from large light colored regions which represent "defects". Then, since C-scan technique incorporates the effects of ultrasonic attenuation ( $\mathrm{dB}$ loss), histograms of these $\mathrm{dB}$ losses are obtained for each composite plate.

In $\mathrm{C}$-scan analysis, there is a maximum tolerable $\mathrm{dB}$ difference from the average $\mathrm{dB}$ loss value. Thus, the regions having a $\mathrm{dB}$ loss higher than the maximum tolerable loss can be referred as "voids" or "defects". C-scan histograms of composite plates indicated that the minimum dB loss value was $27 \mathrm{~dB}$, and a tolerance level of $15 \mathrm{~dB}$ was used for convenience. Thus, losses higher than $42 \mathrm{~dB}$ can be referred to as "defects" including preexisting voids in the resin and voids formed during resin injection.

Percentages of these $\mathrm{dB}$ losses $(\geq 42 \mathrm{~dB}$ ), which can be also referred to as percentage of "defects", are determined and compared in Figure 4. It is seen that, when vacuum is applied during molding, amount of "defects" (which might be formed due to the bubbles in the resin or entrapped air at the fiber/matrix interface) decreases considerably. The decreases in the percentages of "defects" are 63, 61, and $54 \%$ for the mold temperatures of $25^{\circ}, 60^{\circ}$, and $120^{\circ} \mathrm{C}$, respectively.

Mechanical properties of this set of specimens are given in Figure 5. As depicted in Figure 5(a), tensile tests reveal that in presence of vacuum assistance, there are 6 
and $5 \%$ improvements in tensile strength for $25^{\circ}$ and $60^{\circ} \mathrm{C}$ mold temperature conditions, respectively. It is shown in Figure $5(\mathrm{~b})$ that impact properties are improved as much as 23 and $26 \%$ for $25^{\circ}$ and $60^{\circ} \mathrm{C}$ mold temperatures by the application of vacuum, whereas the enhancement is only $4 \%$ for the $120^{\circ} \mathrm{C}$ mold temperature.

It can be concluded that the enhancement in mechanical properties is solely due to the reduction in the percentage of the "defects" or "voids" under vacuum. In fact, reductions are more than $60 \%$ for the mold temperatures of $25^{\circ}$ and $60^{\circ} \mathrm{C}$. SEM analysis also indicated that there exist more microvoids in the structure when the specimens are produced without the assistance of vacuum even at the optimum mold temperature of $60^{\circ} \mathrm{C}$.

\section{CONCLUSION}

Among the mold temperatures of $25^{\circ}, 40^{\circ}, 60^{\circ}, 80^{\circ}, 100^{\circ}$, and $120^{\circ} \mathrm{C}$, specimens produced with a mold temperature of $60^{\circ} \mathrm{C}$ possess $16 \%$ higher tensile strength and $43 \%$ higher Charpy impact toughness when compared to the specimens produced at $25^{\circ}$ and $120^{\circ} \mathrm{C}$ mold temperatures. Therefore, optimum mold temperature is found to be $60^{\circ} \mathrm{C}$ which leads to an optimum resin viscosity and gel time to enable the ventilation of pre-existing bubbles and newly formed micro voids during production.

C-scan inspection indicated that percentage of $\mathrm{dB}$ loss above a certain level which can be referred as "defects" is decreased by $60 \%$ with the assistance of vacuum ( 0.03 bar) during molding. The application of vacuum is found to provide around $5 \%$ increased tensile strength and $26 \%$ higher Charpy impact toughness.

\section{ACKNOWLEDGEMENTS}

The authors would like to thank to Baris Inc. for providing their RTM facilities, TAI Tusas Aerospace Industries for C-Scan facilities, and TEMSA Automotive Ind. Co. for mechanical and thermal analysis.

\section{REFERENCES}

[1] Chang, C.Y. , Hourng, L.W. , Chou, T.Y. Journal of Reinforced Plastics and Composites, No:25(10), pp 1027-1037 (2006)

[2] Yu, H.W. , Young, W.B. Journal of Composite Materials, No:31(11), pp 11131140 (1997)

[3] Johnson, R.J. and Pitchumani, R. Composites Science and Technology, No:63, pp 2201-2215 (2003)

[4] Lundstrom, T.S. and Gebart, B.R. Polymer Composites, No:15, pp 25-33 (1994)

[5] Hayward, J.S. and Harris, B. SAMPE Journal, No:26, pp 39-46 (1990) 


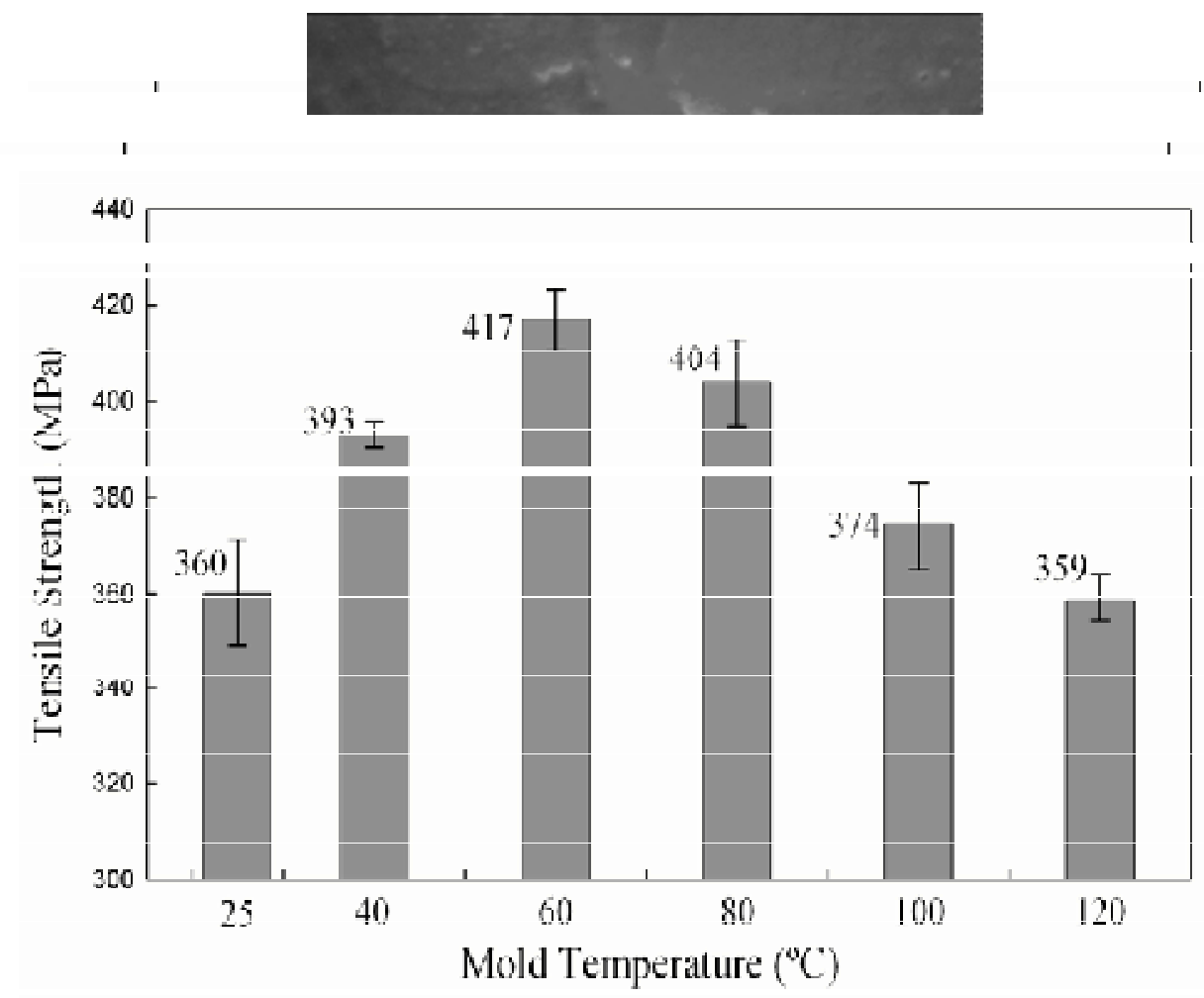

(a)

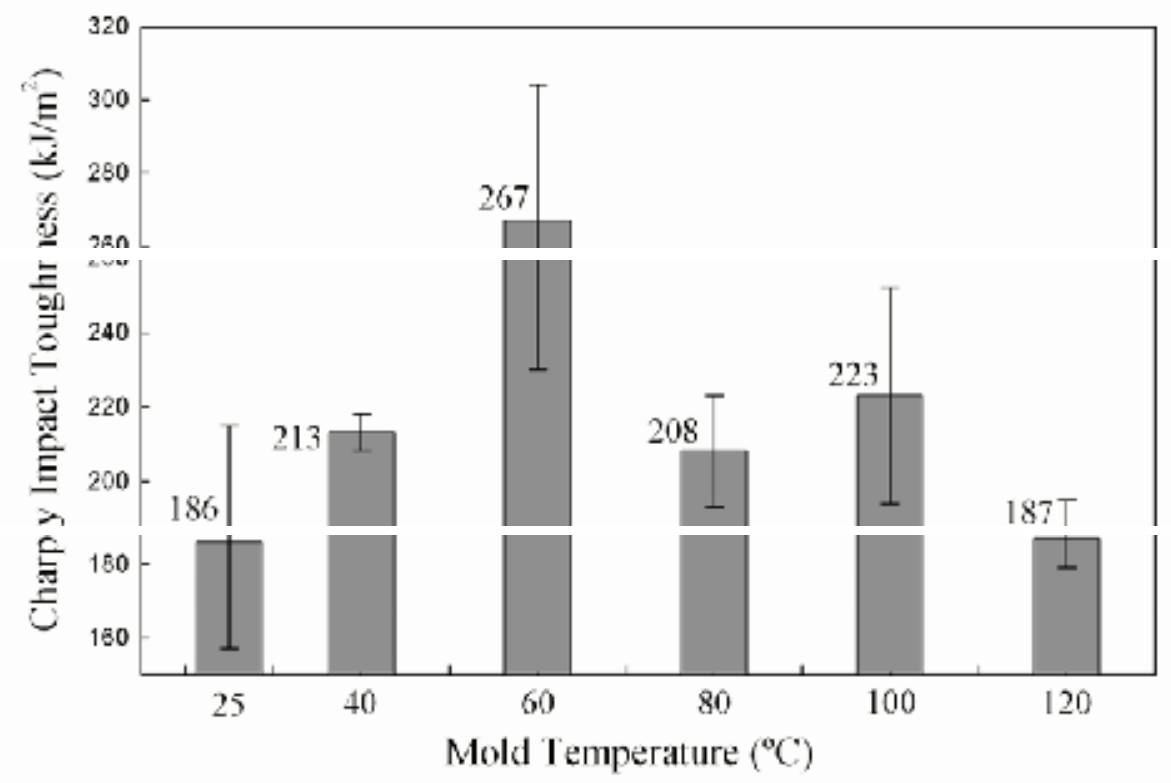

(b)

Figure 1. (a) Tensile Strength and (b) Charpy Impact Toughness of the composite specimens produced using different mold temperatures under vacuum 

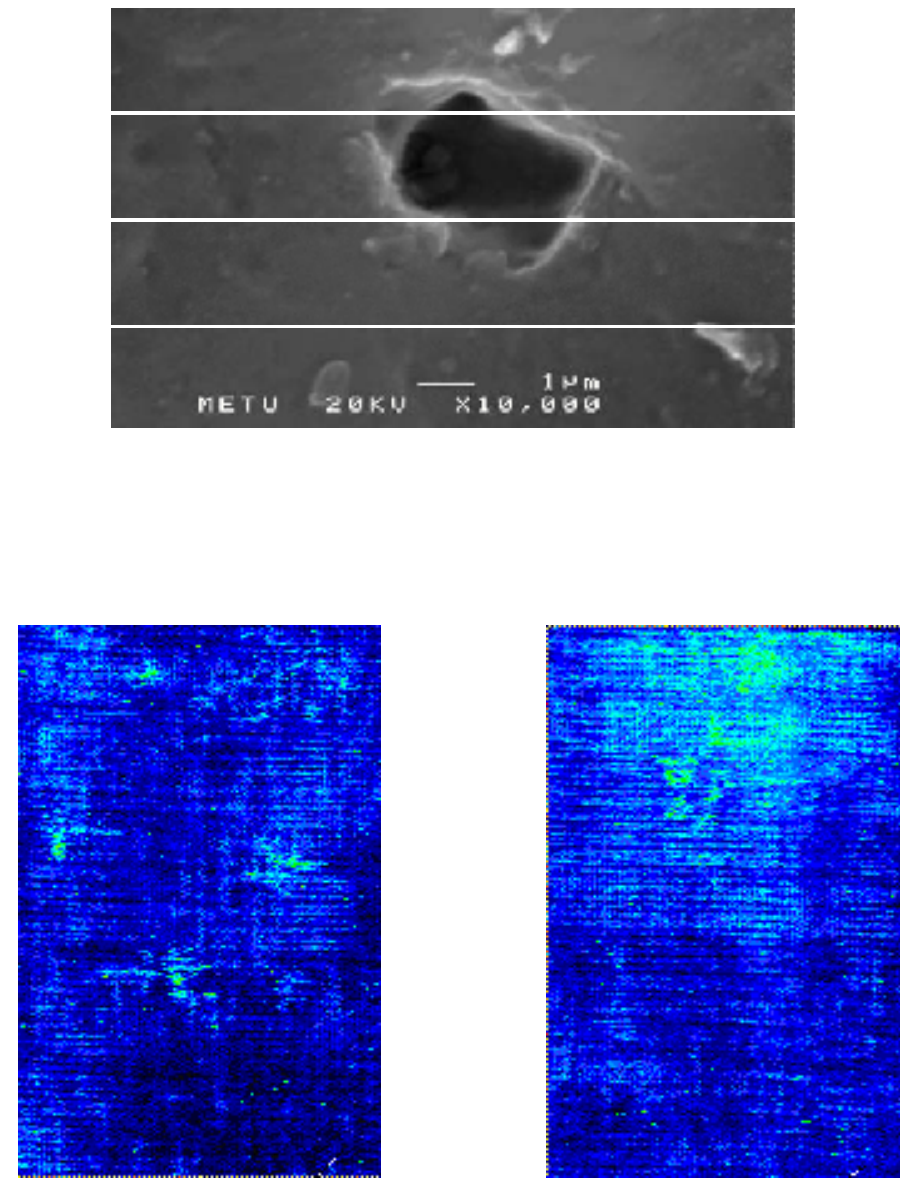

Figure 2. An example of a microvoid formed in the matrix

(a)

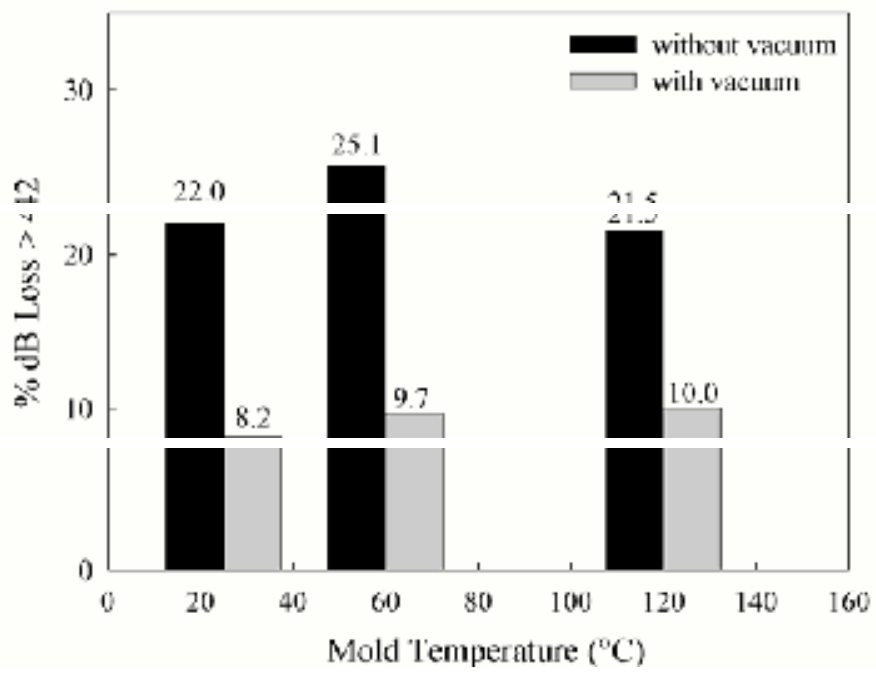

(b)

Figure 3. Examples of C-Scan images (a) with vacuum and (b) without vacuum 


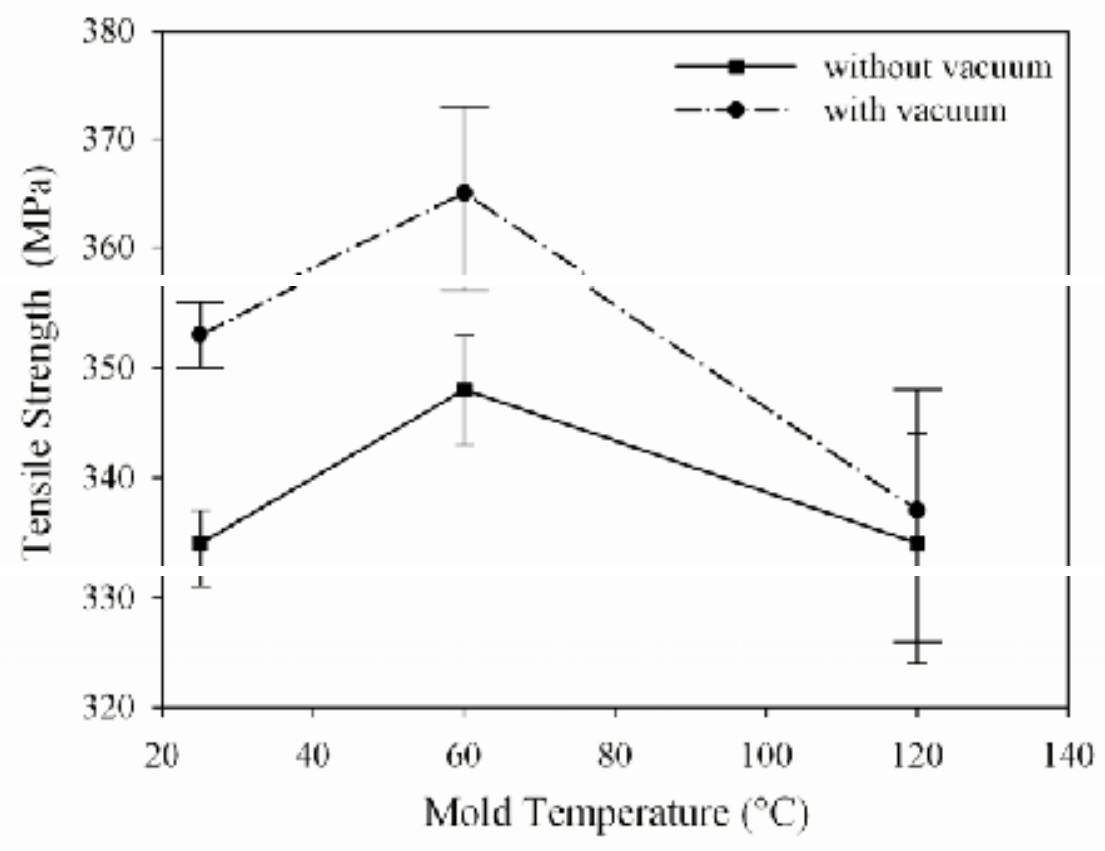

Figure 4. Percentages of dB loss values extracted from C-Scan Histograms

(a)

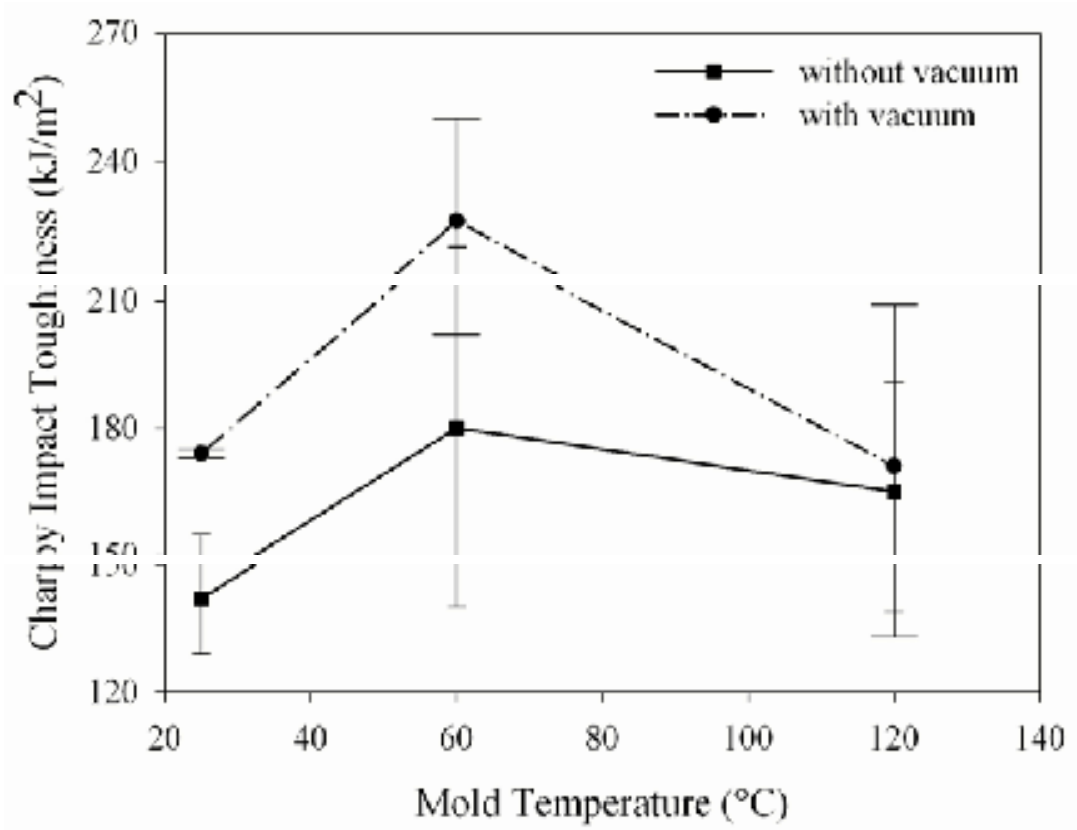

Figure 5. (a) Tensile Strength and (b) Charpy Impact Toughness of the specimens when vacuum is applied to the mold 